\title{
Computer Simulation of Adsorption of Fullerene on Graphene
}

\author{
Abror Ulukmuradov ${ }^{1}$, Ishmumin Yadgarov ${ }^{1, *}$, Vasiliy Stelmakh, Farid Umarov² \\ ${ }^{1}$ Arifov Institute of Ion-Plasma and Laser Technologies, Uzbekistan Academy of Sciences, Tashkent, Uzbekistan \\ ${ }^{2}$ Kazakh-British Technical University, Almaty, Kazakhstan
}

(Received 14 January 2021; revised manuscript received 15 April 2021; published online 20 April 2021)

\begin{abstract}
In the present work, the adsorption of fullerene $\mathrm{C}_{60}$ onto the surface and edges of defect-free graphene was studied by computer simulation within the framework of classical molecular dynamics. The computer model of single defect-free fullerene $\mathrm{C}_{60}$ was built by the energy minimization method using the secondgeneration Brenner potential (REBO), and the cohesive energy of each carbon atom in fullerene was determined. For consideration of fullerene adsorption on the graphene surface, a computer model of "infinite" defect-free graphene was obtained by the same method with a glance of periodic conditions for boundary atoms. For fullerene adsorption on graphene edges to be considered, a computer model of defect-free nanographene was constructed. It was obtained that fullerene $\mathrm{C}_{60}$ adsorption on the graphene surface can be realized by different ways. The geometrical characteristics of fullerene $\mathrm{C}_{60}$ adsorbed on the graphene surface were obtained. It was established that fullerene is better adsorbed on the armchair edge of nano-graphene and worse on the "corner" atom of nano-graphene. The binding energy for adsorption on the nano-graphene edge can be almost twice as large as the highest binding energy of adsorption on the graphene surface, and stronger deformation of the fullerene shape is observed.
\end{abstract}

Keywords: Fullerene, Graphene, Adsorption, Binding energy, Brenner potential, FORTRAN.

DOI: 10.21272/jnep.13(2).02025

PACS numbers: 34.50. - s, 68.49.Sf

\section{INTRODUCTION}

Interest in studying the processes of interaction of atoms and clusters with metal crystals and elements of carbon nanostructures is continuously growing. This is due both to the need for a better understanding of the mechanisms of various processes that accompany the interaction of atoms and clusters with the surface and thin films of crystals, and to the technical needs associated with the manufacture of micro- and nanoelectronics elements and materials with given properties, as well as the development of methods for diagnosis and surface modification. That is why in recent years, the processes of interaction of cluster particles with the surface of a solid body have become increasingly interesting for experimenters and theorists working in the field of physics of interaction of atomic particles with the surface of a solid body [1-5].

Fullerenes are an independent allotropic form of carbon as isolated molecules that are self-organized in the form of convex closed polyhedrons composed of the even number of three-coordinated atoms of carbon. Defect-free fullerenes consist of geometrically regular hexagons (Fig. 1a) and geometrically regular pentagons (Fig. 1b), and defect-free graphene is composed of hexagons only (Fig. 2). The number of carbon atoms $(n)$ in fullerene obeys some regularity, namely $n=32,44,50$, $58,60,70,72,78,80,82,84$ etc. The most stable fullerene has 60 atoms of carbon and is denoted as $\mathrm{C}_{60}$. It is followed by fullerene $\mathrm{C}_{70}$ that differs from fullerene $\mathrm{C}_{60}$ by inserting a belt of 10 carbon atoms into the equatorial region of $\mathrm{C}_{60}$; as a result, the $\mathrm{C}_{70}$ molecule becomes elongated and resembles a rugby ball. Higher fullerenes containing a greater number of carbon atoms (up to 400) are formed in much smaller amounts and often have a rather complex isomeric composition. Among fullerenes, fullerene $\mathrm{C}_{60}$ has the highest symmetry and the highest stability. It is formed by 20 hexagons and 12 pentagons with carbon atoms at their vertices. Another structural feature of this fullerene is that it has an internal cavity whose diameter, taking into account the size of carbon atoms, is about 5 angstroms $(\AA)$; owing to that, atoms of other elements or even small molecules can be inside fullerene.
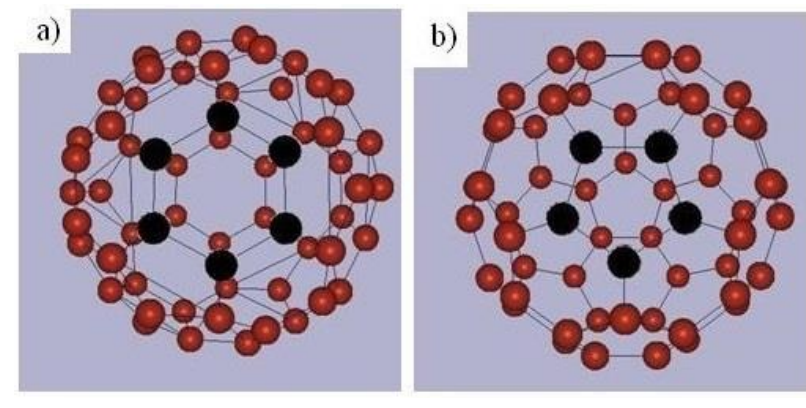

Fig. 1 - Atomic structures as an example of fullerene $\mathrm{C}_{60}$ : a) hexagon and b) pentagon marked by black circles

The unique possibilities of fullerene are broadened when fullerene is combined with other atoms and molecules, and endofullerenes are of special interest when additional atoms, for example, alkali metal ones, are in the inner cavity of fullerene. However, the practical application of fullerenes and endofullerenes in nanoengineering is due to the question what substrate will be used for fullerene structures. Such substrates can be the surfaces of silicon carbide crystals, silicon, diamond and graphene that, in view of miniaturization, is more successful since their thickness is one atomic layer. In addition, defect-free graphene having a two-dimensional hexagonal carbon crystalline lattice (Fig. 2) is a unique

\footnotetext{
*yadgarovishmumin@gmail.com
} 
object with distinctive physical properties [6] and can be selected as a substrate for integrated chips. In the present work, the adsorption of fullerene $\mathrm{C}_{60}$ onto the surface of defect-free graphene is studied by computational simulation within the framework of classical molecular dynamics.

\section{METHOD OF SIMULATION AND RESULTS}

First, a computer model of single defect-free fullerene $\mathrm{C}_{60}$ was built by the energy minimization method using the second-generation Brenner potential (REBO) well describing the carbon structures [7]. The initial disposition of fullerene atoms for this computer model was created by the program [8] written in FORTRAN and the coordinates of fullerene $\mathrm{C}_{60}$ atoms were used as numerical values. Used in our calculations, the program having the REBO potential was taken from [9]; this program was written in FORTRAN and has an auxiliary program to minimize. For this, the energy minimization method is implemented; in addition, the program makes it possible to use the so-called periodic conditions imposed on boundary ions of some structure. It was found that the cohesive energy of each carbon atom in fullerene is equal to 6.8 electron volts $(\mathrm{eV})$.

A computer model of "infinite" defect-free graphene was constructed; this model was intended to consider fullerene adsorption on the graphene surface. For that purpose, a rectangular graphene section with 112 carbon atoms was taken (Fig. 2; and see details and justification of this model in [10]). The initial disposition of graphene atoms for this computer model was created by the program [11] written in FORTRAN; the coordinates of graphene atoms were defined by such an algorithm as if graphene had a rectangular shape for different possible sizes. Then, by the same method of energy minimization with the Brenner potential, under periodic conditions for boundary atoms, a computer model of infinite defect-free graphene with the distance between its nearest atoms of $1.4 \AA$ and the cohesion energy $E_{g}$ of each atom of $7.4 \mathrm{eV}$ was obtained. The fact that $E_{g}>E_{f}$ indicates that "infinite" defectfree graphene is a more stable structure than defectfree fullerene $\mathrm{C}_{60}$

The "infinite" defect-free graphene model itself does not take into account the finite size of graphene sheets because this model has no edge atoms. Meanwhile under laboratory conditions, graphene sheets of different, but finite sizes are obtained. Those graphene sheets have some quantity of edge atoms $N_{b}$ that is proportional to the perimeter $P$ of a graphene sheet and some quantity of internal atoms $N_{i}$ that is proportional to the area $S$ of a graphene sheet. Supposing $R$ is a mean radius of a graphene sheet, it is possible to write $N_{b} \sim P=k_{b} R$ and $N_{i} \sim S=k_{i} R^{2}$, where $k_{b}$ and $k_{i}$ are the constants depending on the shape of a graphene sheet, for example, for the circular shape $k_{b}=2 \pi$ and $k_{i}=\pi$ $(\pi=3.1416 \ldots)$. A share of the edge atoms is $n_{b}=N_{b} / N_{i} \sim 1 / R$ and hence only for graphene sheets of sufficiently large sizes the edge atoms can be neglected, while for graphene with small sizes allowing them to be considered as nanodimensional $\left(\sim 10^{-9} \mathrm{~m}\right)$ ones, it is impossible to neglect the edge atoms.

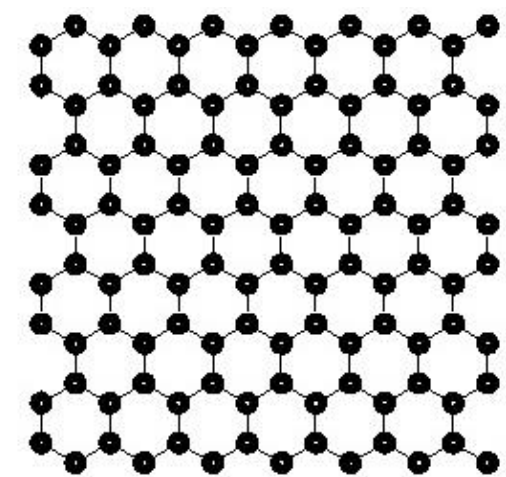

Fig. 2 - The atomic structure of defect-free 112-atom rectangular region of graphene consisting of hexagons under periodic boundary conditions

For fullerene adsorption on graphene edges to be considered, a computer model of defect-free nanographene was constructed. This model was constructed in the same way as the model of "infinite" defect-free graphene, but without imposing the boundary conditions on the edge atoms. As a result, nano-graphene with the distance between its nearest atoms of approximately $1.4 \AA$ (see Fig. 3) was obtained. Cohesion energy of 82 inner atoms (i.e. atoms having chemical bonds with three neighboring atoms) is equal to $7.4 \mathrm{eV}$; only the energy of the remaining 2 inner atoms of carbon is $7.8 \mathrm{eV}$. The values of the cohesion energy for other atoms are presented in Fig. 3. Note that the edge atoms on zigzag or armchair edges of nano-graphene have lower cohesion energy than the inner atoms, since the edge atoms are chemically connected only with two or one neighboring atoms while the inner ones with three. In general, for this 112-atom nano-graphene the number of the edge atoms is $N_{b}=28$, the total number of inner atoms is $N_{i}=84$ and hence the share of the edge atoms is $n_{b}=33 \%$, i.e. the share of the edge atoms is significant. Note that this nano-graphene is called defect-free in the sense that its inner atoms are located in an ideal hexagonal structure of graphene.

After obtaining computer models of single defectfree objects (fullerene $\mathrm{C}_{60}$, "infinite" graphene and nano-graphene), fullerene adsorption was first studied on graphene and then on its edges. For the initial disposition of fullerene atoms relative to graphene atoms to be set, the program [8] with required modification was used, as well as the program [11]. The latter gives such initial Cartesian coordinates $x_{k}, y_{k}, z_{k}(k=1,2, \ldots$, 112) of atoms of 112-atom graphene that the Cartesian coordinates are $z_{k}=0$, i.e. graphene is in the Cartesian plane $z=0$; the graphene armchair-edge is parallel to the $O x$ axis and the zigzag-edge is along the $O y$ axis. The initial coordinates of graphene atoms were unchanged; for required spatial disposition of fullerene $\mathrm{C}_{60}$ relative to graphene only the Cartesian coordinates $\left(x_{i}, y_{i}, z_{i}, i=1,2, \ldots, 60\right)$ of fullerene atoms were changed with the program [8].

Within the program [8], the parallel transfer of fullerene is set by $x_{i}=x_{i}+A, y_{i}=y_{i}+B, z_{i}=z_{i}+C$, where $A, B$ and $C$ are the coordinates of the parallel transfer vector. Spatial rotation of fullerene around the Cartesian axis $O x$ to an angle $\varphi$ is set by the relations: $x_{i}^{R}=x_{i}, y_{i}^{R}=y_{i} \cos \varphi-z_{i} \sin \varphi, z_{i}^{R}=y_{i} \sin \varphi-z_{i} \cos \varphi$, where 
$i=1,2, \ldots, 60$ and $x_{i}^{R}, y_{i}^{R}$ and $z_{i}^{R}$ are the Cartesian coordinates of fullerene atoms after this rotation. The spatial rotations of fullerene around the Cartesian axes $O y$ and $O z$ are set in a similar way. The result of the program [8] operation is the files in the format "xyz" and in the format "PSI Format 1.0" readable by the program Amira 2.2 [12] that visualizes the obtained atomic structures.

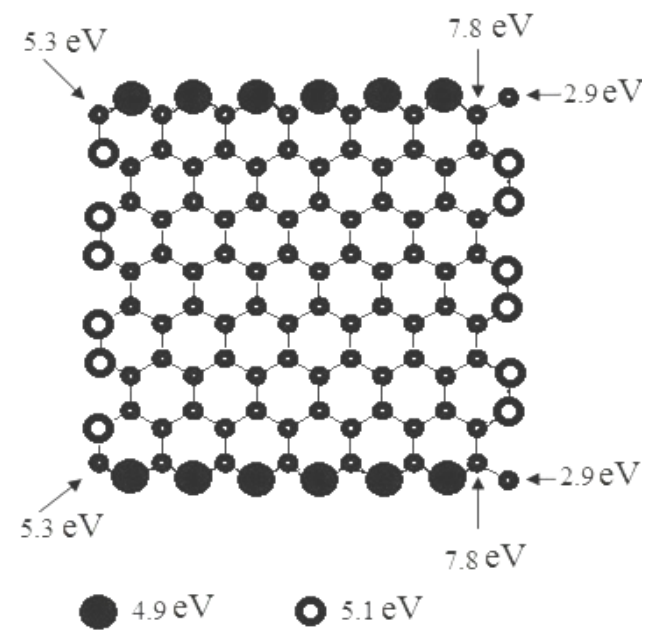

Fig. 3 - Rectangular 112-atom nano-graphene. The horizontal edges are zigzag ones; the vertical edges are armchair ones. Atoms with the cohesion energy different from $7.4 \mathrm{eV}$ are chosen to be larger or shown by arrows with their cohesion energy

Visual viewing with Amira 2.2 allows you to select the desired initial disposition of fullerene relative to graphene. For the initial coordinates of fullerene atoms, when the adsorption of fullerene on the graphene surface is simulated, such coordinates of the parallel transfer vector $(A, B, C)$ were selected that fullerene visually was approximately in the center of graphene and at such a short distance from graphene that between atoms of fullerene and atoms of graphene there would be interaction. Then the spatial rotation of the initial coordinates of fullerene atoms allowed to select different ways of interaction of fullerene with graphene. In the case of simulating the interaction between fullerene and nano-graphene edge, such coordinates of the parallel transfer vector $(A, B, C)$ were chosen that the fullerene center was in the same plane as graphene; besides there would be "contact" of fullerene with the following areas of nano-graphene: 1) armchair-edge, 2) zigzag-edge and 3) nano-graphene corner.

It should be noted that not all the initial dispositions of fullerene relative to graphene we created proved to be successful in the sense that after simulation of their interaction with the program [9] there will be a desired result: fullerene interacts with graphene without their destruction, since in some cases either there was no interaction between fullerene and graphene, or strong changes in the structure of fullerene and graphene corresponded to their destruction. The best way to detect such unsuccessful initial dispositions of fullerene relative to graphene is to view the final structure obtained by the minimization method with the program [9]. A small subroutine write_amira in FORTRAN was added to the program [9]. Its call leads to the appearance of a file coordAM in the format "PSI Format 1.0" available for viewing by Amira 2.2.

An auxiliary program was also compiled in FORTRAN to read the Cartesian coordinates of the fullerene atom and determine:

1 ) the coordinates of the fullerene center $x_{c}, y_{c}$ and $z_{c}$ according to the formulas

$$
x_{c}=\sum_{i=1}^{60} x_{i} / 60, y_{c}=\sum_{i=1}^{60} y_{i} / 60 \text { and } z_{c}=\sum_{i=1}^{60} z_{i} / 60 \text {; }
$$

2 ) the distance $R_{i}$ of the $i$-th atom of fullerene to the fullerene center according to the formula $R_{i}=\left(x_{i}-x_{c}\right)^{2}+\left(y_{i}-y_{c}\right)^{2}+\left(z_{i}-z_{c}\right)^{2}$, where $i=1,2, \ldots, 60$;

3 ) the maximum $R_{\max }$ and the minimum $R_{\min }$ radii of fullerene according to the expressions $R_{\max }=\max \left\{R_{i}\right\}$ and $R_{\min }=\min \left\{R_{i}\right\}$, where $i=1,2, \ldots, 60$;

4) the value $R_{\max } / R_{\min }$.

Note that for free ideal fullerene $\mathrm{C}_{60} R_{i}=R_{F}(i=1$, $2, \ldots, 60)$ is valid, where $R_{F}$ is the fullerene radius. If fullerene interacts or has defects, then for $i$-th atom of fullerene $R_{i} \neq R_{F}$ is possible. Therefore, one can say about maximum and minimum radii of fullerene and the value of $R_{\max } / R_{\min }>1$.

It was obtained that fullerene $\mathrm{C}_{60}$ adsorption on the graphene surface can be realized by different ways; below only 5 ones are given with indication of their names, if any [13]

I) Interaction of one atom of fullerene with one atom of graphene (C-ATP).

II) Interaction of fullerene hexagons and graphene (C-RING).

III) Interaction of two neighboring atoms of fullerene and two neighboring atoms of graphene (BRI).

IV) Interaction when the center of fullerene hexagon is located over the graphene atom (C-RING2).

V) Interaction of two nearest non-neighboring atoms of fullerene and two nearest non-neighboring atoms of graphene.

The geometrical characteristics of adsorbed fullerene which were obtained by analyzing the results of computer simulation by the above 5 ways of adsorption are given in Table 1.

Table 1 - Geometrical characteristics of fullerene $\mathrm{C}_{60}$ adsorbed on the graphene surface

\begin{tabular}{|c|c|c|c|c|c|}
\hline & \multicolumn{5}{|c|}{ Ways of adsorption } \\
\cline { 2 - 6 } & I-C-ATP & II-C-RING & III-BRI & IV-C-RING2 & V \\
\hline Radius, averaged, $\AA$ & 3.60 & 3.61 & 3.60 & 3.61 & 3.60 \\
\hline Radius, maximum, $\AA$ & 3.91 & 3.98 & 3.91 & 3.88 & 3.88 \\
\hline Radius, minimum, $\AA$ & 3.53 & 3.50 & 3.50 & 3.48 & 3.47 \\
\hline $\begin{array}{c}\text { Ratio of the maximum radius } \\
\text { to the minimum one }\end{array}$ & 1.108 & 1.137 & 1.117 & 1.115 & 1.118 \\
\hline
\end{tabular}


Since the radius of free fullerene $\mathrm{C}_{60}$ is equal to $3.60 \AA$ and its spherical symmetry leads to the fact that the values of its maximum and minimum radii are equal to each other and their ratio is 1, then, according to Table 1, as a result of adsorption the spherical symmetry of fullerene $\mathrm{C}_{60}$ is violated and this violation of symmetry depends on a way of adsorption on the graphene surface.

The binding energies and the adsorption distances for adsorbed fullerene $\mathrm{C}_{60}$ were also obtained; they were compared with available experimental and theo- retical results (see Table 2). It was experimentally obtained in [14] that the binding energy of fullerene $\mathrm{C}_{60}$ and graphene is equal to $0.85 \mathrm{eV}$ and the least distance between fullerene $\mathrm{C}_{60}$ atoms and graphene ones is equal to $2.9 \AA$ which can be considered as a measurable experimental value of the adsorption distance. In [13], by three first-principles methods PBE, PBE-D2 and optB $86 \mathrm{~b}$ the binding energy and the adsorption distance were obtained for the adsorption ways from I to $\mathrm{IV}$; the geometrical changes in adsorbed fullerene $\mathrm{C}_{60}$ are not presented in that paper.

Table 2 - Comparison of the obtained results (selected by bold) with those of the first-principles calculations and experimental data

\begin{tabular}{|c|c|c|c|c|c|c|}
\hline & \multirow[b]{3}{*}{$\begin{array}{c}\text { Way of } \\
\text { adsorption }\end{array}$} & \multicolumn{4}{|c|}{ Method of calculation } & \multirow{3}{*}{ 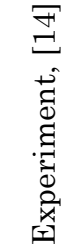 } \\
\hline & & \multirow[b]{2}{*}{ 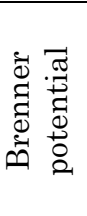 } & \multicolumn{3}{|c|}{ First-principles [13] } & \\
\hline & & & 兵 & $\begin{array}{c}\stackrel{N}{A} \\
\text { जी } \\
\text { ติ }\end{array}$ & $\begin{array}{l}00 \\
\infty \\
0 \\
01 \\
0 \\
0\end{array}$ & \\
\hline \multirow{5}{*}{ 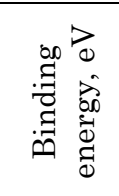 } & I,C-ATP & 1.08 & 0.15 & 0.91 & 1.28 & \multirow{5}{*}{0.85} \\
\hline & II, C-RING & 0.77 & 0.13 & 0.83 & 1.17 & \\
\hline & III, BRI & 1.07 & 0.13 & 0.84 & 1.20 & \\
\hline & IV, C-RING2 & 0.06 & 0.13 & 0.90 & 1.23 & \\
\hline & $\mathrm{V}$ & 0.84 & - & - & - & \\
\hline \multirow{5}{*}{ 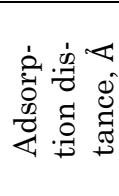 } & I,C-ATP & 2.62 & 3.50 & 2.82 & 2.81 & \multirow{5}{*}{2.9} \\
\hline & II, C-RING & 2.69 & 3.79 & 3.32 & 3.35 & \\
\hline & III, BRI & 2.69 & 3.57 & 3.10 & 3.14 & \\
\hline & IV, C-RING2 & 2.19 & 3.53 & 3.15 & 3.16 & \\
\hline & $\mathrm{V}$ & 2.22 & - & - & - & \\
\hline
\end{tabular}

Table 3 - Characteristics of fullerene $\mathrm{C}_{60}$ adsorbed on graphene edges

\begin{tabular}{|l|c|c|c|}
\hline $\begin{array}{l}\text { Variant number of adsorption } \\
\text { on the graphene edge }\end{array}$ & 1 & 2 & 3 \\
\hline Binding energy, eV & 2.0 & 2.6 & 0.4 \\
\hline Fullerene radius, averaged, $\AA$ & 3.60 & 3.61 & 3.60 \\
\hline Fullerene radius, maximum, $\AA$ & 3.96 & 4.03 & 3.84 \\
\hline Fullerene radius, minimum, $\AA$ & 3.52 & 3.24 & 3.52 \\
\hline Ratio of max radius to min one & 1.125 & 1.244 & 1.091 \\
\hline
\end{tabular}

As seen from Table 2, the results are in good agreement with experimental data and results obtained from first principles. It should be noted that from all the ways of adsorption the first one I is the best, because fullerene $\mathrm{C}_{60}$ has the highest energy of binding with graphene and the adsorbed fullerene is less deformed as a result of its interaction with graphene.

The computer models of fullerene $\mathrm{C}_{60}$ and nanographene were used to study fullerene adsorption on graphene edges. Three variants of fullerene adsorption on graphene edges were considered (Fig. 4):

1) Fullerene is adsorbed in the middle of the zigzag edge of nano-graphene;

2) Fullerene is adsorbed in the middle of the armchair edge of nano-graphene;

3) Fullerene is adsorbed near a "corner" atom of nano-graphene with the cohesion energy of $2.9 \mathrm{eV}$.

In all these variants of adsorption it was supposed that the geometrical center of fullerene is in the plane in which nano-graphene is located. After specifying the initial arrangement of defect-free fullerene and nano- graphene by the method of energy minimization, the binding energy of adsorbed fullerene with graphene was obtained, as well as other results presented in Table 3. From Table 3, it follows that fullerene is better adsorbed on the armchair edge of nano-graphene and worse on the "corner" atom of nano-graphene.
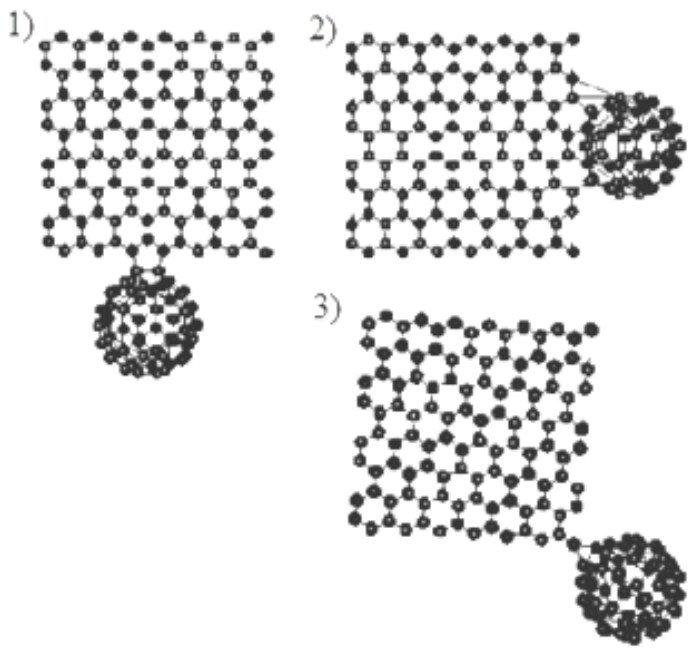

Fig. 4-Visual representation of the interaction of fullerene $\mathrm{C}_{60}$ adsorbed in 1) the middle of the zigzag edge of nanographene, 2) the middle of the armchair edge of nano-graphene and 3) an edge "corner" atom of nano-graphene. These visual pictures are obtained with the program Amira 2.2

The binding energy of adsorption on the nanographene edge can be almost twice as large as the high- 
est binding energy of adsorption on the graphene surface, and stronger deformation of the fullerene shape is observed.

\section{CONCLUSIONS}

We developed a computer model of single defect-free objects: fullerene $\mathrm{C}_{60}$, "infinite" graphene, and nanographene. The adsorption of fullerene by the graphene surface and its edges was considered. To study the adsorption of fullerene on graphene, the models of fullerene and "infinite" graphene were brought together at the required distance with different geometric positions of fullerene relative to the graphene surface. The energy minimization method was applied to the resulting model using the Brenner potential and periodic bound- ary conditions on the edge graphene atoms. Three variants of fullerene adsorption by the nano-graphene edge were considered. The simulation results show that when fullerene is adsorbed by the graphene edge, the fullerene molecule deforms, losing its spherical symmetry. The maximum deformation of a fullerene molecule was observed during its adsorption by the "armchair" graphene edge, due to its binding by a larger number of graphene atoms.

\section{ACKNOWLEDGEMENTS}

The authors are grateful to A.A. Dzhurakhalov for fruitful help and discussions. This work was done with the financial support of grant No. OT-F2-46 provided by Arifov Institute of Ion-Plasma and Laser Technologies.

\title{
REFERENCES
}

1. E.S. Parilis, L.M. Kishinevsky, N.Yu. Turaev, B.E. Baklitzky, F.F. Umarov, V.Kh. Verleger, S. Niznaya, I.S. Bitensky, Atomic Collisions on Solid Surfaces (North-Holland: Amsterdam: 1993).

2. U. Kutliev, M. Karimov, B. Sadullaeva, M. Otaboev, Compusoft 7, 2749 (2018).

3. M.K. Karimov, Kh.J. Matchonov, K.U. Otaboeva, M.U. Otaboev, e-J. Surf. Sci. Nanotechnol. 17, 179 (2019).

4. U.O. Kutliev, M.K. Karimov, M.U. Otaboev, Inorg. Mater.: Appl. Res. 11, 503 (2020).

5. M.K. Karimov, U.O. Kutliev, Sh.K. Ismailov, M.U. Otaboev, e-J. Surf. Sci. Nanotechnol. 18, 164 (2020).

6. A.K. Geim, K.S. Novoselov, Nat. Mater. 6, 183 (2007).

7. D.W. Brenner, O.A. Shenderova, J.A. Harrison, S.J. Stuart, B. Ni, S.B. Sinnot, J. Phys.: Condens. Matter. 14, 783 (2002).

8. V.G. Stelmakh, I.D. Yadgarov, N.Yu. Turaev, A.N. Ulukmuradov, Certificate of Computer Program Registration No DGU 05185 , The Republic of Uzbekistan, Registration Date 03.04.2018.

9. http://www.eng.fsu.edu/ dommelen/research/nano/brenner lindex.html\#advinfo

10. A.A. Dzhurakhalov, F.M. Peeters, Carbon 49, 3258 (2011).

11. V.G. Stelmakh, I.D. Yadgarov, Certificate of Computer Program Registration No DGU 03641, The Republic of Uzbekistan, Registration Date 05.04.2016.

12. https://www.thermofisher.com/uz/en/home/industrial/elect ron-microscopy/electron-microscopy-instrumentsworkflow-solutions/3d-visualization-analysissoftware/amira-life-sciences-biomedical.html

13. S. Laref, A.M. Asaduzzaman, W. Beck, P.A. Deymier, K. Runge, L. Adamowicz, K. Muralidharan, Chem. Phys. Lett. 582, 115 (2013).

14. H. Ulbricht, G. Moos, T. Hertel, Phys. Rev. Lett. 90, 095501 (2003).

\section{Комп'ютерне моделювання адсорбції фулерену на графені}

\author{
Abror Ulukmuradov ${ }^{1}$, Ishmumin Yadgarov ${ }^{1}$, Vasiliy Stelmakh ${ }^{1}$, Farid Umarov ${ }^{2}$ \\ ${ }^{1}$ Arifov Institute of Ion-Plasma and Laser Technologies, Uzbekistan Academy of Sciences, Tashkent, Uzbekistan \\ ${ }^{2}$ Kazakh-British Technical University, Almaty, Kazakhstan
}

\begin{abstract}
У роботі адсорбція фулерену $\mathrm{C}_{60}$ на поверхні та краях бездефектного графена вивчалася за допомогою комп'ютерного моделювання в рамках класичної молекулярної динаміки. Комп'ютерна модель одиночного бездефектного фулерену $\mathrm{C}_{60}$ побудована методом мінімізації енергії з використанням потенщіалу Бреннера другого покоління (REBO), і визначена енергія зв'язку кожного атома вуглецю у фулерені. Для розгляду адсорбції фулерену на поверхні графена тим самим методом отримано комп'ютерну модель "нескінченного" бездефектного графена з урахуванням періодичних умов для граничних атомів. Для розгляду адсорбції фулерену на графенових краях побудовано комп'ютерну модель бездефектного нанографена. Встановлено, що адсорбція фулерену $\mathrm{C}_{60}$ на поверхні графена може бути реалізована різними способами. Отримано геометричні характеристики фулерену $\mathrm{C}_{60}$, адсорбованого на поверхні графена. Встановлено, що фулерен краще адсорбуеться на краю нанографена типу "крісла 3 ручками" і гірше на "кутових" атомах нанографена. Енергія зв'язку для адсорбції на краю нанографена може бути майже вдвічі більшою, ніж найвища енергія зв'язку адсорбції на поверхні графена, і спостерігається сильніша деформація форми фулерену.
\end{abstract}

Ключові слова: Фулерен, Графен, Адсорбція, Енергія зв'язку, Потенціал Бреннера, FORTRAN. 